\title{
REFLECTION
}

\section{Steven Ablon, $M D$}

Chestnut Hill, MA, USA.

J Gen Intern Med 24(9): 1080

DOI: $10.1007 / \mathrm{s} 11606-009-0974-0$

(c) Steven Ablon 2009

\section{Health}

My patient offers me a chocolate from a box beside his bed.

He hopes I will find a white hard center of health.

But I look

for a soft cherry infused with Grand Marnier

The body is deceptive, a half moon tumor on the hip could be an abscess easily drained.

I want to put his death back in the box, retie the bow. 